\title{
Povos Indígenas no contexto do ensino superior: os desafios do acesso e da permanência na UFPR
}

\author{
LAYS GONÇALVES DA SILVA
}

\section{Conhecendo os sujeitos da pesquisa e o desenvolvimento da proposta metodológica}

O primeiro contato que tive com o tema da educação diferenciada nas Instituições de Ensino Superior (IES) se deu já no início da graduação, quando, em 2010, dois indígenas Xokleng ingressaram, em Ciências Sociais, na mesma turma que eu, na UFPR. Porém, ao final do primeiro semestre eles se ausentaram, e não retornaram no seguinte.

Deste início algumas questões chamaram-me atenção e foram amadurecidas no decurso do trajeto de formação, culminando na proposta de pesquisa da qual resultou a monografia de graduação. Eu achava muito difícil o curso, além das dificuldades de entendimentos dos processos institucionais, estudava muito para conseguir atingir a média nas avaliações e acompanhar o ritmo de leituras e a carga horária de atividades diurna, que implicava sobrecarga com o trabalho fora da universidade. Estes eram fatores que me fizeram pensar sobre que tipo de questões levaram aqueles indígenas Xokleng ${ }^{1}$ a deixar o curso: seriam estas as mesmas razões que me importunavam "sendo eles indígenas"? Escrevo com aspas pois até o momento do término do trabalho de conclusão, ainda estava com dificuldade de perceber como as questões que dificultam a permanência no ensino superior para um indígena ou não-indígena mudam ora em conteúdo ora em nossas motivações de estar ali, mas quanto ao mérito de "permanecer" e se formar, eu também tinha questóes, então ficava a pergunta: o que de fato nos diferencia?

No primeiro ano deixei meu emprego, o qual era de contrato precário e pelo qual recebia muito pouco, porque consegui me inserir no Programa Institucional de Bolsas de Iniciação à Docência (PIBID) como bolsista, programa que me garantiu uma bolsa, relações comprometidas de trabalho e amizade, além de seu propósito central: me permitiu desenvolver capacidades e me deu segurança para

1 Um deles, é o caso de registrar aqui, era Marcondes Namblá, que, em $1^{\circ}$ de janeiro de 2018, foi brutalmente espancado e veio a falecer em Penha, no litoral de Santa Catarina. Marcondes era liderança indígena, graduou-se na UFSC e se tornara professor. 
lecionar um $\mathrm{dia}^{2}$. Eu morava com meus pais, meus gastos existentes eram limitados, com isso passei a dar mais conta das leituras exigidas no curso.

Nos primeiros anos comecei a fazer parte do movimento estudantil, e por conta disso conheci outros dois indígenas que eram bastante engajados no movimento indígena, dentro e fora da universidade. Um deles se tornou meu amigo, e viu na minha pesquisa uma possibilidade de mobilizar a questão das políticas de permanência da universidade para os indígenas, discussão que já vinha ocorrendo entre um grupo deles de estudantes dos campi Litoral e de Curitiba. Assim, nesse contexto, vi a possibilidade de contribuir em um processo de reflexão em curso.

Participei de reuniões do Programa de Ensino Tutorial Conexão de Saberes (PET), reuniões do grupo de estudantes com a Pró-Reitoria de Assuntos Estudantis (PRAE), nas quais fui apresentada ora como pesquisadora ora como militante, a vários outros indígenas e a quem mais estivesse. Sempre que tinha algum encontro, meu amigo, da etnia Guarani, me apresentava e apontava a importância da pesquisa a ser feita. Às vezes não se tratavam de reuniões formais, com o tempo se tornaram muito mais encontros informais, no Restaurante Universitário (RU), em momentos de lazer. Com isso fui criando vínculos com outras colegas também indígenas, com as quais nutro até hoje grande amizade. Desta forma, em dado momento, encontrei certa dificuldade para saber como proceder na pesquisa. O que seria uma boa etnografia? Fazia-me essa pergunta, principalmente, porque tinha dificuldade inclusive para reencontrar o conjunto de acadêmicos. Por vezes não tinha todas as informações sobre reuniões, ainda que meu amigo tentasse me deixar informada, pois ele também tinha a organização dele e não podia sempre me acompanhar. Bem, eram 12 estudantes indígenas no PET, eu convivi com indígenas que eram do Programa ou outros próximos a eles, no entanto, soube pela indígena responsável pelo acolhimento dos acadêmicos indígenas que havia um total de 40 matriculados

Diante da importância do tema e do pouco tempo de pesquisa, precisei delimitar um grupo com o qual eu iria trabalhar. Desta forma, a partir da bibliografia sobre a realidade da UFPR, busquei traçar o perfil dos estudantes e das condições em que se encontravam. Esta bibliografia me conduziu a trabalhar com estudantes de cursos do Setor de Ciências da Saúde matriculados na UFPR. As informações da bibliografia encontrada que me conduziram a esta definição traziam dados apenas até $2013^{3}$, estes seriam os dados mais recentes.

O primeiro motivo deste recorte foi o fato de a maioria dos egressos serem de cursos ligados à saúde, dos 11 formados até 2013, foram três na medicina, dois em odontologia, um em nutrição (CERETTA, FREITAS, NOGUEIRA, ROSSETO, 2013). Outro fator, foi identificar que a primeira estudante egressa foi uma Kaingang da Terra Indígena (TI) de Pinhalzinho, no curso de odontologia (PEREZ GIL, 2011).

2 Esse programa, existente desde 2010, propicia um diálogo entre acadêmicos e professores da universidade e a comunidade das escolas, estando presente em todas as universidades federais. Infelizmente, o governo atual ameaça encerrá-lo.

3 Num momento seguinte à monografia me dei conta de que as informações até 2013 coincidiam com o momento em que entrou em vigor a Lei 12.711/2012, a qual interferiu no Plano de Metas da Universidade - Resolução 37/04 no que tange às cotas raciais e sociais. Embora a Lei 12.711/2012 não versasse sobre os indígenas, os dados produzidos e publicados pela universidade se tratavam do balanço até 2013 sobre todo o plano de metas. Ou seja, muitos textos que encontrei mesmo de pessoas que se envolveram mais diretamente com o PET Indígena e o NUEI, tinham dados somente até 2013. 
O alto interesse por medicina foi visto logo no primeiro vestibular, de 2004/2005, quando ainda não havia o critério de ser uma vaga por curso todos os cinco aprovados naquele ano se matricularam em medicina (BEVILAQUA, 2004). Um quarto ponto é que embora a medicina seja visada pelos candidatos indígenas, em 2009 fica definido pela Resolução 37/04 Conselho Universitário da UFPR (COUN-UFPR $)^{4}$ serem ofertadas anualmente dez vagas, mas para dez cursos diferentes, e distribuídas aos ingressantes pela escolha sequenciada do primeiro lugar ao décimo5. Há relatos de indígenas que queriam ingressar no curso de medicina mas não passaram em primeiro lugar para poder escolher primeiro - fala de uma Kaingang, diante da alta procura. Desta forma, resta escolher entre outros cursos também da saúde ou de áreas de currículos com os quais, na maioria das vezes, não são familiarizados. Outro elemento é o fato de as vagas anuais do curso de medicina serem ofertadas ou não a partir da disposição da Faculdade de Medicina, havendo uma alternância de ano em ano, de forma não periódica, diferentemente de outros cursos que ofertam permanentemente.

Outro ponto interessante foi a ausência de estudantes de cursos ligados ao Setor de Ciências da Saúde nas reunióes que pude participar, no NUEI e com a PRAE, muito por conta da carga horária exigida. Todos os cursos da saúde ficam nos campi de Curitiba o que permite observar o ingresso e a permanência em relação à moradia, mobilidade, alimentação, num mesmo contexto - todavia a universidade oferta vagas para o Setor Litoral e Toledo, também. E, por fim, o tema da saúde é acionado no movimento indígena por conta da realidade nas terras indígenas, assim como a educação ${ }^{6}$, contribuindo para a escolha de concentrar a pesquisa neste âmbito dos cursos da saúde.

\section{Breve histórico: da política indigenista à política educacional}

A busca por parte dos indígenas pelo ensino superior no Brasil é anterior à política diferenciada implementada pelos governos estaduais e federal, mas com as políticas de acesso ao ensino superior público, a presença indígena nas Instituições de Ensino Superior (IES) se amplia significativamente.

A elaboração dessas políticas específicas tem início no ensino básico diferenciado, o qual foi estruturado e estabelecido a partir de três momentos legislativos fundamentais. O primeiro seria a aprovação da Constituição de 1988, na qual pela primeira vez o Estado reconhece os povos originários como sujeitos de seus próprios direitos, de língua e crenças próprias, e de direito originário sobre suas terras; e também reconhece suas organizações como parte legítima de ingresso na defesa desses direitos (art. no 231 e 232). O segundo, seria o deslocamento da responsabilidade da educação indígena para

\footnotetext{
4 A Resolução 37/04 COUN-UFPR, previa cinco vagas em 2005 e 2006, sete vagas em 2007 e 2008 e dez vagas a partir de 2009 , a serem preenchidas a partir de processo seletivo diferenciado e exclusivo. Esta informação será retomada ao longo do texto.

5 Depois da experiência do primeiro vestibular, a partir de 2009 havendo 10 vagas disponíveis, passou a serem dez diferentes vagas, para dez cursos diferentes, não podendo mais de um indígena ingressar num mesmo ano em um mesmo curso. Esta questão última não está especificada na Resolução, esta informação vem pelos próprios indígenas no processo de matrícula em que não podem escolher um curso que alguém que passou em melhor colocação já escolheu.

6 Cito aqui a educação também pois como aponto na sequência, a licenciatura intercultural é proposta pelos indígenas, no entanto, não é um modelo de curso ofertado pela UFPR.
} 
o Ministério da Educação (MEC), em 19917 , antes função apenas da Fundação Nacional do Índio (FUNAI) a qual passa a contribuir mais objetivamente na qualificação da política educacional junto aos povos indígenas. Por fim, a Lei de Diretrizes e Bases da Educação Nacional (LDB), em 1996, a qual reconhece o processo educacional específico, e disciplina sobre a educação indígena prevendo o ensino escolar bilíngue e intercultural, visando a reafirmação da identidade étnica, a valorização dos saberes indígenas e o fortalecimento sociocultural.

Anteriormente a esses marcos, a FUNAI em sua criação, em 1967, ainda se orientava pela rede de escolas instaladas no período do Serviço de Proteção aos Índios (SPI) com ensino de primeiras letras e atividades para os futuros trabalhadores nacionais, com ensino bilíngue calcado no modelo evangelizador da Summer Institute of Linguistic, métodos esses que perduraram em sua gestão. $\mathrm{O}$ antigo Serviço de Proteção ao Índio e Localização dos Trabalhadores Nacionais (SPILTN), depois chamado apenas SPI, foi o primeiro órgão estatal criado em período republicano de relação com os indígenas, em 1910, numa perspectiva política assimilacionista e civilizatória, a qual identificava o indígena de forma homogênea como categoria transitória que deveria se transformar no "trabalhador nacional". A partir de seu completo desvirtuamento com casos de corrupção, foi criada FUNAI, a fim de substituir o órgão. Na sequência, em 1973 é aprovado o Estatuto do Índio, ainda, também, cumprindo com a linha assimilacionista de "integração dos povos indígenas".

Os marcos legislativos a partir de 1988 com a LDB de 1996 trazem uma nova perspectiva educacional principalmente por terem sido elaborados junto a profissionais da educação, organizações indígenas, técnicos e gestores governamentais, ONGs, comunidade científica e militantes de todo o país, preocupados com a autonomia e valorização da cultura como fio condutor da política indígena.

A educação escolar indígena prevista na LDB aponta a necessidade de formação de professores indígenas para lecionar nas escolas, o que gera um forte viés de demanda de criação de cursos específicos ligados às universidades. O Programa de Licenciatura Intercultural Indígena (PROLIND), de 2004, é o primeiro programa do governo federal voltado para a formação bilíngue de professores indígenas em universidades públicas federais e estaduais. O segundo viés perpassa a necessidade de haver indígenas formados nos demais cursos para autonomia na articulação entre saberes e demandas indígenas diante da relação com o Estado (SOUZA LIMA, 2007). Até aqui há uma confluência de ações por parte dos indígenas e de muitos outros agentes.

No Paraná, foi criada em 2001 a Lei Estadual 13.134/2001 que institui o Vestibular Interinstitucional dos Povos Indígenas do Estado do Paraná, a qual prevê vagas suplementares nas universidades estaduais para as etnias residentes na federação. Em 2004, a UFPR firmou convênio com a Secretaria de Estado de Ciência e Tecnologia (SETI) aderindo ao Vestibular, e subsequente a esta decisão, aprovou a Resolução interna 37/04 COUN-UFPR, “Plano de Metas de Inclusão Racial e Social na UFPR”, a qual previa cinco vagas nos anos de 2005 e 2006 abertas para indígenas de todas as etnias do território nacional e para qualquer curso da universidade, sete vagas em 2007 e 2008, e dez vagas a partir de 2009,

7 https://pib.socioambiental.org/pt/c/politicas-indigenistas/educacao-escolar-indigena/da-funai-para-o-mec Acessado em 8 de ago. de 2017. 
a serem preenchidas a partir de um processo seletivo exclusivo, junto às demais estaduais, organizado pela Comissão Universidade para Índios, CUIA, prevista na Lei.

No primeiro vestibular diferenciado em que a UFPR participou, se inscreveram 75 indígenas, provenientes das etnias Gavião, Guarani, Kaingang, Kanamari, Terena, Ticuna e Tucano, sendo 36 Kaingang e 5 Guaranis, apenas 10 vindos do estado do Paraná. Portanto a maioria dos vestibulandos são provenientes de outros estados da federação - AM, MS, PA, RS, SC. Os cursos de maior procura foram medicina (10), odontologia (9), enfermagem (9), administração (6), agronomia (6), direito (5), educação física (5) (BEVILAQUA, 2004). Pelos dados encontrados, até 2013 adentraram 78 indígenas na UFPR, entre formados (11), cancelamentos (6), abandonos (14) e trancamentos (4), e sendo 40 matriculados (CERETTA. FREITAS. ROSSETTO. NOGUEIRA, 2013).

Em 2009 é criada pela Pró-Reitoria de Graduação e Educação Profissional (PROGRAD) o Núcleo de Acompanhamento das Políticas Afirmativas (NAPA), com o intuito de acompanhar os estudantes que entravam pelas políticas afirmativas e o desenvolvimento da política na universidade. Em 2010 houve uma reestruturação por meio da qual foi criado o Núcleo Universitário de Educação Indígena (NUEI), com foco no acolhimento e acompanhamento dos estudantes indígenas, e composto por professores, servidores técnicos e estudantes indígenas.

Sobre os auxílios permanência, anteriormente à Lei 12.711/2012, a qual prevê dos recursos do MEC uma bolsa para indígenas e quilombolas, a UFPR garantia também bolsas do Programa de Bolsa Permanência (PROBEM) para um valor de moradia e isenção no Restaurante Universitário. Pelos relatos dos indígenas, com a Lei 12.711/2012, a UFPR não garante mais o auxílio moradia do PROBEM, mas mantém o auxílio do RU. No início do convênio da UFPR com a SETI para entrada no Vestibular, um termo de cooperação foi feito entre UFPR e FUNAI em 2004, o qual previa auxílio de $\mathrm{R} \$ 210,00$ por parte da UFPR, e de $\mathrm{R} \$ 730,00$ da FUNAI, mas há poucas informações sobre este termo (PAULINO, 2008).

A universidade conta com um Programa de Ensino Tutorial Indígena Conexões de Saberes/ MEC - PET, desde 2010, coordenado por Eduardo Harder, docente do Setor Litoral, programa que garante 12 bolsistas, e que preza serem estes dos campi Curitiba e Litoral. No Setor Litoral da UFPR também há o Laboratório de Interculturalidade e Diversidade (LAID), coordenado por Ana Elisa de Castro Freitas e Eduardo Harder, com o propósito de diálogo permanente entre estudantes indígenas e não-indígenas e comunidade acadêmica. Estas duas políticas e o NUEI, o qual possui um espaço físico em Curitiba, assim como o LAID no Setor Litoral, se propõem como espaços de interação, formação e acompanhamento dos acadêmicos indígenas em seu trajeto na universidade.

\section{As entrevistas}

O formato das entrevistas não foi padronizado em perguntas e respostas, mas por uma conversa conduzida por basicamente três questões, as quais relacionadas a vivências anteriores que os motivaram a tomar a decisão de cursar o ensino superior (família, terra indígena, aldeia urbana, escola, experiência em outras universidades, amigos), à aprovação e momento da chegada na cidade de Curitiba para se 
estabelecer e então começar os estudos, e a impressões sobre sua presença enquanto indígena em sala de aula. Desta forma, a apresentação de cada um na pesquisa se deu de forma singular, as entrevistas ocorreram com quatro indígenas dos cursos de odontologia, medicina, enfermagem e terapia ocupacional, sendo respectivamente das etnias Kaiowá, Tupinaki, Terena e Kaingang, matriculados no primeiro semestre de 2016.

As questóes debatidas em cada conversa descrevem sobre o momento da chegada; o contato com outros indígenas; o curso, currículo e sala de aula; da relação com a família no período de estudo; das experiências em outras atividades; e sugestões para a UFPR.

Nomeio cada participante da pesquisa pela primeira letra de seu nome e etnia para facilitar a identificação no decorrer do texto. E. Kaiowá decide como primeira opção o curso de odontologia na UFPR mas aguardava o resultado se ficaria com alguma das dez vagas, e em diálogo com sua mãe dizia não ter segurança se passaria em boa posição para realmente ficar com a vaga de odontologia. E. relata que veio de Dourados-MS, da TI Jaguapiru, não fala a língua materna, mas entende. Em Dourados teve outras duas experiências em uma universidade particular no curso de odontologia, e na UFSM o curso de enfermagem, o qual cursava no momento em que fez o vestibular e o qual prosseguiria, caso não passasse em odontologia. "Se eu não passasse aqui, eu ía continuar enfermagem, eu já tinha um curso que era enfermagem que eu já cursava três anos, porque já tinha oferecido emprego lá, de enfermeiro trabalhando dentro da aldeia. Mas odonto era o meu sonho, eu falava para minha mãe".

N. Tupinaki, estuda medicina, veio de Terra Indígena localizada no Espírito Santo. Desde o ginásio precisou sair da TI para estudar no colégio da cidade, e lá precisou trabalhar logo cedo para se manter. Acabou fazendo um técnico em enfermagem, seu primeiro contato com a área da saúde, mas também começou faculdade de Arquitetura e Urbanismo no mesmo período mas sem concluir. Começou enfermagem na UFMG e na oportunidade do Vestibular da UFPR, entrou em medicina. Dos entrevistados, N. fala a língua materna e se diferencia por ter feito mais vestibulares (Unb, UFPA, UFMG), e conhecer mais dos trâmites burocráticos das universidades. Infelizmente, foi perdido o contato impossibilitando retomar algumas questões levantadas na primeira entrevista.

L. Terena veio da aldeia urbana Aldeinha, de Anastácio-MS, estudou enfermagem e fez reopção de curso para Direito, ocorrendo a entrevista pela sua experiência e posterior decisão por não prosseguir na área da saúde. Filha de pai indígena e mãe não-indígena, L. não conhece a língua paterna (neste caso), mas seu pai e as pessoas mais velhas da aldeia falam. Fez o ensino fundamental na cidade de Aquidauana, cidade vizinha de Anastácio, convivendo lá com a mãe e estudando, e na Aldeinha com os parentes. Quis fazer medicina num primeiro momento, mas embora tenha passado em primeiro lugar, não foi ofertado o curso no respectivo ano, daí a opção pela enfermagem por conselho do irmão. Seu pai fez medicina veterinária, seu irmão cursava medicina na UFT e a mãe atua como enfermeira em Aquidauana.

T. Kaingang estuda terapia ocupacional, da TI Toldo Chimbangue, pertencente ao município de Chapecó-SC. Filha de pai e mãe Kaingang, fala a língua materna mas não fluentemente. Sua mãe era professora na escola na TI, fez faculdade e especialização, incentivando-a a estudar. T. chegou a trabalhar na escola, mas viu que queria algo semelhante na saúde, como psicologia. No ano em que 
tentou o vestibular, outra indígena passou em melhor colocação e pôde escolher psicologia antes que ela, desta forma a escolha por terapia ocupacional foi em partes pela proximidade com psicologia. $\mathrm{T}$. diferentemente dos demais, mora com parte da família em Curitiba, o marido que também estuda na UFPR, e seu filho.

Ao serem perguntados como foram os momentos iniciais em Curitiba, foi unânime o apontamento dos entrevistados de que a matrícula tinha um intervalo razoável até começarem as aulas, e que os auxílios do MEC atrasaram. Com isso precisaram de um auxílio externo a qualquer política institucional para se manter, seja a família, seja por si mesmos (trabalhos precários em Curitiba ou trabalhar anteriormente, como no caso de N.). Outro ponto ressaltado por eles são os contatos para saber onde se estabelecer. No caso de L. e N., precisaram ficar em pensionato, e no caso de L. em situação de vulnerabilidade. T. com a maternidade veio morar em Curitiba com o marido antes de decidir pelo Vestibular, mas ao contar sobre sua história, disse que o marido chegou em Curitiba na rodoviária sem saber exatamente onde era a universidade e com pouco dinheiro, por isso contou com ajuda de outro indígena que aqui já estava, mas este também com dificuldade de ajudar por muito tempo. E. acabou conhecendo L. no dia da matrícula, e L. logo o acolheu em sua casa, mas também precisando dividir as contas da casa.

A experiência em sala de aula seria um terceiro elemento de reflexão, pois varia de acordo com os cursos também. No caso de E., o curso de odontologia exigia um kit de materiais que custavam cerca de 3 mil reais o qual a Pró-Reitoria de Assuntos Estudantis (PRAE) deveria garantir para este estudante indígena que, por sua vez, descobriu esse direito porque a coordenação do curso o informou, e a própria fez a solicitação. Enquanto aguardava seu material, E. conversou com seus colegas de turma para que emprestassem às vezes os seus equipamentos para ele fazer os exercícios, ao que comenta: "Fiquei duas aulas observando, mas na prática é outra coisa”. N. enfrentou dificuldade nas primeiras avaliações pois estudava tudo mas nunca conseguia boas notas. Até que soube que na primeira semana de aula acontece um apadrinhamento dos calouros ${ }^{8}$ por parte dos veteranos da medicina, e que por conta de sua matrícula ter ocorrido um mês depois ele não soube. Entre prós e contras desse apadrinhamento, sabe-se que na universidade há relações hierárquicas entre veterano e calouro, e por vezes violentas, e ao mesmo tempo, tem-se, contudo, orientações sobre o que é importante estudar para as provas, e o que não é necessário despender esforços, no caso da medicina.

T. apresentou a questão de estar vivendo na cidade com seu filho, sendo ele ainda pequeno, e de que ela gostaria que a criança convivesse com os parentes na Terra Indígena. Embora tenha sido acolhida no curso de terapia ocupacional e tenha uma tutora bastante presente, ela identifica essa questão referente a seu filho somada ao custo de viver na cidade, como algo que pode fazê-la trancar ou desistir do curso.

\footnotetext{
8 Termo utilizado entre os estudantes em geral do curso da medicina para a aproximação de um estudante que está há mais tempo (veterano) para com aquele que acaba de chegar (calouro), criando uma relação de acompanhamento seja nas festas de recepção, seja para compartilhar métodos de estudo.
} 
L. em sua experiência na enfermagem percebeu-se mais envolvida pelas disciplinas ligadas a área de humanas, como sociologia e antropologia, dessa forma se entendia num papel de ajudar as pessoas, não mais na área da saúde, mas no Direito.

Tanto E. quanto N. tinham alternativa de estudo caso não passassem no vestibular da UFPR: iriam voltar a estudar enfermagem em suas respectivas universidades, UFSM e UFMG, já L. e T. só possuíam o vestibular da UFPR como perspectiva a curto prazo de estudo. Mas em todos os casos, é visível que uma desistência, um trancamento, não se trata de um simples abandono. As conversas permitem compreender que trata-se de um processo mais amplo e complexo de decisões que envolve dinâmicas coletivas e individuais, étnicas e familiares, motivações e mudanças que fazem parte dessa nova relação com esta universidade.

\section{Apontamentos e sugestôes}

O momento de sugestões para as políticas de ações afirmativas da UFPR emerge na tentativa de refletir sobre o significado de permanência destes indígenas na universidade, da confluência de interesses dos próprios indígenas sobre esta pesquisa, e aqui reúnem-se enunciados levantados, mais de uma vez, desde os momentos de aproximação às entrevistas. Foram levantados pelos indígenas como assuntos primordiais a serem debatidos para caminharmos para um avanço da política, nos quais a universidade deveria deter-se, entre outras coisas: as consequências do atraso das bolsas na chegada, o acolhimento dos novos indígenas na chegada na cidade, a garantia do retorno periódico à terra indígena ou para casa sendo em outra cidade, o ensino sobre os Povos Indígenas nos currículos de todos os cursos da universidade, o diálogo sobre metodologia de ensino, a capacitação dos professores sobre a realidade dos indígenas no Brasil, aulas extra sala de disciplinas do ensino básico para reforço.

\section{Considerações}

A partir das entrevistas e da aproximação inicial foi perceptível como as falas se preocupavam, no que tange a política de permanência da UFPR, com coletividades, seja com os Kaiowá, Kaingang, Terena e Tupinaki de suas localidades de origem os quais podem um dia se interessar pela universidade, seja com todos os indígenas, seus parentes que estão fora e dentro da universidade.

Em cada encontro, percebeu-se que a pesquisa seria mais um canal para poder evidenciar as situações vividas no momento de chegada na universidade, daquilo que cada um precisou passar para conseguir permanecer. O fato de eu, a pesquisadora, vir de movimento social (estudantil) e estar há mais tempo na universidade, permitiu nitidamente uma fluidez no compartilhamento de ideias e reflexões sobre o tema, troca de informações e relatos, de forma tal que, a relação no processo da pesquisa pôde somar e buscou a todo tempo contribuir para dentro de uma organização que já vinham sendo fomentada entre os próprios indígenas.

Ao mesmo tempo era visível como a resiliência enquanto mecanismo de superar e prosseguir estava presente a todo tempo na vida de cada um. Ao passo que eram apontadas falhas da política, elas vi- 
nham acompanhadas de sugestóes para melhoramento junto a relatos de situações de adversidade que foram vivenciadas, enfrentadas e vencidas em dado momento. Na pesquisa de Ana Caroline Goulart, a pesquisadora escreve nas considerações que o sofrimento é transformado em estímulos (GOULART, 2014:177).

E enfim, algumas questões emergiram como possíveis caminhos para ampliação e aprofundamento da pesquisa sobre uma comunidade indígena dentro da universidade. A primeira seria sobre os momentos de uso da categoria genérica indígena e/ou parente em relação aos momentos em que acionam suas etnias específicas nos diálogos entre os próprios estudantes indígenas, visando alargar a compreensão das relações entre si dentro da universidade. E uma segunda questão seria perceber o fato de E. e N. serem homens e L. e T. serem mulheres, quais implicações de gênero podem estar correlacionadas no cotidiano destes e destas indígenas, em seus cursos, com o fato de serem indígenas, as quais sejam relevantes na reflexão sobre o acesso, a permanência e sua formação no ensino superior.

Essas reflexões, tanto a problematização da categoria indígena quanto das implicações relacionadas a um recorte de gênero, se revelaram interessantes para melhor compreensão sobre as vivências destes indígenas na universidade e merecem atenção em pesquisas futuras.

\section{Lays Gonçalves da Silva é graduada em Ciências Sociais pela Universidade Fe- deral do Paraná e mestranda no Programa de Pós-Graduação em Antropologia na mesma instituição.}

\section{REFERÊNCIAS BIBLIOGRÁFICAS}

BEVILAQUA, Ciméa Barbato. 2004. O Primeiro Vestibular Indígena na UFPR. In Campos Revista de Antropologia Social. Curitiba, Paraná, n 05/2, p. 181-185.

CERETTA, Laura Moreira, FREITAS, Ana Elisa de Castro, NOGUEIRA, Kelvy Kadge Oliveira e ROSSETTO, Ligia Maria. 2013. Educação Superior de Indígenas: acesso e permanência da UFPR. In Anais IV Encontro de Educação Superior Indígenas do Paraná. Guarapuava, Paraná.

GOULART, Ana Caroline. 2014. Experimentar, contestar e refazer-se: caminhos de sonhos e enfrentamentos percorridos por acadêmicos Kaingang e Guarani na Universidade Estadual de Londrina - PR. Curitiba, PR. Dissertação. (Mestrado em Antropologia Social). UFPR.

PAULINO, Marcos. 2008. Povos indígenas e ações afirmativas: o caso do Paraná. Rio de Janeiro. Dissertação (Mestrado em Educação). UFRJ.

PEREZ GIL, Laura. 2011. Relatório: núcleo de acompanhamento das políticas afirmativas da ufpr informações referentes ao alunado indígena em 2010. In Relatório de pesquisa: políticas afirmativas no ensino superior (versão preliminar). UFPR, Curitiba. 
SOUZA LIMA, Antonio Carlos de. 2007. Educação superior para indígenas no brasil sobre cotas e algo mais. Artigo apresentado em Seminário Formação Jurídica e Povos Indígenas Desafios para uma educação superior. Belém, PA-Brasil. 


\title{
POVOS INDÍGENAS NO CONTEXTO DO ENSINO SUPERIOR: OS DESAFIOS DO ACESSO E DA PERMANÊNCIA NA UFPR
}

Resumo: O presente texto se propõe a uma síntese do meu trabalho de conclusão de curso de graduação em Ciências Sociais, intitulado "Indígenas estudantes na UFPR: os desafios do acesso e permanência no ensino superior" - realizado na Universidade Federal do Paraná (UFPR), sob orientação de Edilene Coffaci Lima, em 2016. Neste trabalho trago uma reflexão sobre a presença indígena na universidade tratado a partir das experiências plurais de discentes que entraram por meio do Vestibular Interinstitucional dos Povos Indígenas do Estado do Paraná. Tal trabalho constitui-se do exercício de buscar uma compreensão geral do processo de institucionalização da política de escolarização diferenciada para os povos indígenas no ensino superior no Brasil, observadas as experiências vividas por estudantes indígenas de cursos do Setor de Ciências da Saúde na UFPR.

Palavras-chave: Povos Indígenas; Ensino Superior; Acesso e Permanência; UFPR

\section{INDIGENOUS PEOPLES IN THE CONTEXT OF HIGHER EDUCATION: THE CHALLENGES OF ACCESS AND PERMANENCE IN UFPR}

\begin{abstract}
The present text proposes a synthesis of my final paper to complete a degree course in Social Sciences, entitled "Indigenous students in UFPR: the challenges of access and permanence in higher education" - held at the Federal University of Paraná (UFPR), under orientation of Edilene Coffaci de Lima, in 2016. In this work I bring a reflection about the indigenous presence in the university from the plural experiences of students who entered through the Interinstitutional Entrance Exam of the State of Paraná for Indigenous People. This work constitutes from the exercise of seeking a general understanding of the institucionalization process of the differentiated education policy for Indigenous People in higer education in Brazil, based on the experiences of indigenous students from the courses of Health Sciences Sector at UFPR.Keywords: Indigenous People; Higher Education; Access and Permanence; UFPR
\end{abstract}

RECEBIDO EM: 02/07/2017

APROVADO EM: 09/12/2017 
112 CAMPos V.17 N.2 jul.dez.2016 